\title{
How Does Schooling Influence Maternal Health Practices? Evidence from Nepal
}

\section{Citation}

Rowe, Meredith L., Bijaya Kumar Thapa, Robert LeVine, Sarah LeVine, and Sumon K. Tuladhar. 2005. "How Does Schooling Influence Maternal Health Practices? Evidence from Nepal."

Comparative Education Review 49 (4): 512-533.

\section{Published Version}

doi:10.1086/432769

\section{Permanent link}

http://nrs.harvard.edu/urn-3:HUL.InstRepos:13041215

\section{Terms of Use}

This article was downloaded from Harvard University's DASH repository, and is made available under the terms and conditions applicable to Other Posted Material, as set forth at http:// nrs.harvard.edu/urn-3:HUL.InstRepos:dash.current.terms-of-use\#LAA

\section{Share Your Story}

The Harvard community has made this article openly available.

Please share how this access benefits you. Submit a story.

Accessibility 


\title{
How Does Schooling Influence Maternal Health Practices? Evidence from Nepal
}

\author{
MEREDITH L. ROWE, BIJAYA KUMAR THAPA, ROBERT LEVINE, SARAH LEVINE, \\ AND SUMON K. TULADHAR
}

\section{Introduction}

Women's schooling is associated with much of the world's improvement in child survival and maternal and child health since $1960 .{ }^{1}$ Evidence for these associations is widely interpreted as representing a causal influence of formal education on health. ${ }^{2}$ The relationships of variations in female school attendance at the levels of individuals, populations, and historical periods to reproductive health outcomes raise new questions for comparative educational research concerning the process involved. This article reports the results of a survey designed to test a theoretical model positing that literacy skills acquired by girls in school are retained into their adult years, facilitating their exposure to public health messages in the media, which in turn influence the health knowledge affecting their health behavior as mothers.

This survey was conducted in Nepal, a low-income country in which both mass schooling and demographic transition are recent developments, using direct assessment of literacy skills instead of the self-reports or imputation from school attainment levels often used in demographic and health surveys. After a brief review of the relevant studies to provide an empirical basis for

Clifford Meyers, then of UNICEF Nepal, organized this survey and provided technical guidance for it. Data collection and analysis were funded by UNICEF Nepal and carried out by the Center for Research, Innovation and Development in Education (CERID), Tribhuvan University, Kathmandu, Nepal. The analyses reported herein were supported by grants from the William T. Grant Foundation and the Spencer Foundation to the Harvard Graduate School of Education (Robert A. LeVine, principal investigator).

${ }^{1}$ C. T. Bicego and J. T. Boerma, "Maternal Education and Child Survival: A Comparative Study of Survey Data from 17 Countries," Social Science and Medicine 36 (1993): 207-28; John Caldwell, "Education as a Factor in Mortality Decline: An Examination of Nigerian Data," Population Studies 33 (1979): 395-413, "Routes to Low Mortality in Poor Countries," Population and Development Review 12 (1986): 171-214, and "How Is Greater Maternal Education Translated into Lower Child Mortality?" Health Transition Review 4 (1994): 224-29; John Cleland and J. van Ginneken, "Maternal Education and Child Survival in Developing Countries: The Search for Pathways of Influence," Social Science and Medicine 27 (1988): 1357-68; K. Haddon and B. London, "Educating Girls in the Third World: The Demographic, Basic Needs and Economic Benefits," International Journal of Comparative Sociology 37 (1996): 31-46; Emily Hannum and Claudia Buchmann, The Consequences of Global Educational Expansion: Social Science Perspectives (Cambridge, MA: American Academy of Arts and Sciences, Project on Universal Basic and Secondary Education, 2003).

${ }^{2}$ For example, see S. Mehrotra and Richard Jolly, eds., Development with a Human Face (Oxford: Clarendon, 1997); UNICEF, The State of the World's Children, 1999 (New York: Oxford University Press, 1998); Amartya Sen, Development as Freedom (New York: Knopf, 1999).

Comparative Education Review, vol. 49, no. 4.

(C) 2005 by the Comparative and International Education Society. All rights reserved.

0010-4086/2005/4904-0001\$05.00 
our theoretical model, we present the background to the survey from previous Nepal health research, followed by the methods and findings of the survey and discussion of the results.

Previous Research

The causal relation between school-acquired literacy skills, maternal health knowledge and behavior, and child outcomes has been examined using direct assessments of literacy in Morocco, Guatemala, and other developing countries. For example, Paul Glewwe analyzed the data on 1,495 children and their mothers in Morocco included in a World Bank Living Standards Measurement Survey (LSMS) and found that child height for age (an inverse measure of the stunting caused by chronic malnutrition) was explained by mother's functional literacy in Arabic and her health knowledge, with socioeconomic factors controlled. ${ }^{3}$ Veena Khandke, Kathleen Gorman, and Ernesto Pollitt analyzed data on 266 children and their mothers who participated in a nutritional supplementation study conducted by the Institute of Nutrition in Central America and Panama (INCAP) from 1969 to 1977 in four Spanish-speaking villages of rural eastern Guatemala. ${ }^{4}$ The mothers took a literacy test based on local materials, and the children were monitored for respiratory illness during the first 4 years of life. ${ }^{5}$ Khandke, Gorman, and Pollitt found that the children of mothers with 4-6 years of schooling had less respiratory illness than those whose mothers had 1-3 years, with socioeconomic variables controlled, and that maternal literacy predicted child's respiratory illness at 4 years of age, with controls for maternal school attainment as well as socioeconomic status (SES).

Other findings come from the work of Robert LeVine and colleagues at the Project on Maternal Schooling of the Harvard Graduate School of Education. This project included community-level studies on this topic in Mexico, Zambia, Nepal, and Venezuela. ${ }^{6}$ In these studies, the scores from direct

\footnotetext{
${ }^{3}$ Paul Glewwe, "How Does Schooling of Mothers Improve Child Health? Evidence from Morocco" (Living Standards Measurement Study Working Paper no. 128, World Bank, Washington, DC, 1997), and "Why Does Mother's Schooling Raise Child Health in Developing Countries? Evidence from Morocco," Journal of Human Resources 34 (1999): 124-59.

${ }^{4}$ Veena Khandke, Ernesto Pollitt, and Kathleen Gorman, "The Role of Maternal Literacy in Child Health and Cognitive Development in Rural Guatemala" (poster presented at the biennial meetings of the Society for Research in Child Development, Albuquerque, NM, April, 1999).

${ }^{5}$ Kathleen Gorman and Ernesto Pollitt, "The Contribution of Schooling to Literacy in Guatemala," International Review of Education 43 (1997): 283-98.

${ }^{6}$ Results of studies in Mexico are presented in Emily Dexter, Sarah LeVine, and Patricia Velasco, "Maternal Schooling and Health-Related Language and Literacy Skills in Rural Mexico," Comparative Education Review 42 (1998): 139-62; results of studies in Zambia are presented in Katherine Stuebing, "Maternal Schooling and Comprehension of Child Health Information in Urban Zambia: Is Literacy a Missing Link in the Maternal Schooling-Child Health Relationship?" Health Transition Review 7 (1997): 151-72; results of studies in Nepal are presented in Robert A. LeVine, Sarah LeVine, and Beatrice Schnell, "Improve the Women: Mass Schooling, Female Literacy and Worldwide Social Change," Harvard Educational Review 71 (2001): 1-50; Robert A. LeVine, Sarah LeVine, Meredith Rowe, and Beatrice Schnell-Anzola, "Maternal Literacy and Health Behavior: A Nepalese Case Study," Social Science and Medicine 58 (2004): 863-77; and results from studies in Venezuela are presented in Beatrice Schnell-
} 
assessment of literacy skills (reading comprehension and academic language proficiency) in local samples of at least 160 mothers were predicted by school attainment, with other socioeconomic factors controlled; literacy scores predicted comprehension of public health media messages, with schooling as well as SES controlled. In the Nepal and Venezuela studies, mothers' literacy skills predicted their ability to provide an organized health narrative of a recent illness, with controls, and in Nepal maternal literacy was related to the ability to explain the label on a package of oral rehydration salts (for diarrhea in young children). These findings and those mentioned above suggest that literacy skills acquired in school, directly assessed in a variety of urban and rural samples across the world, improve the abilities of women to understand health information and interact effectively with health practitioners.

Furthermore, schooling and the literacy skills learned in school may help women access information in the print and broadcast media. Studies focusing on media access have shown a link between exposure to mass media and health outcomes. For example, Duncan Thomas and colleagues, in a study of the effect of education on child height for age and sex in Brazil, found that regular access to radio, television, and newspapers was a significant predictor of child height, explaining almost all of the effect of maternal schooling. ${ }^{7}$ The authors conclude "the availability and processing of information plays a critical role in the transmission of the benefits of education." "These results underscore the importance of examining media as a possible pathway from schooling to health knowledge and practices.

Thus far, empirical research supports the plausibility of a literacy and information access pathway from the formal education of women to health in poor and developing countries. Many of the links in that pathway, however, are unspecified or unmeasured in research conducted to date. Further study is needed to connect maternal schooling, literacy skills, and media access with health outcomes. To address these needs, we designed the survey reported in this article.

Nepal Research

Nepal in the year 2000 was a particularly appropriate context for an investigation of the processes by which maternal schooling affects reproductive health and related variables. In Nepal, the expansion of women's schooling and the demographic transition are in progress but far from complete. National surveys of women show robust associations of educational attainment

Anzola, Meredith Rowe, and Robert A. LeVine, "Literacy as a Pathway between Schooling and HealthRelated Communication Skills: A Case Study of Venezuelan Mothers," International Journal of Educational Development 25 (2005): 19-37.

${ }^{7}$ Duncan Thomas, J. Strauss, and M. Henriques, "How Does Mother's Education Affect Child Height?” Journal of Human Resources 26 (1991): 183-211.

${ }^{8}$ Ibid., 209. 
with reduced child mortality and fertility, higher age at marriage, increased utilization of health services, and greater exposure to health media. ${ }^{9}$ Although Nepal had an adult female literacy rate of only 24 percent in $2000,{ }^{10}$ girls' schooling was spreading rapidly, particularly in districts of the Kathmandu Valley as well as Kaski and Chitwan. In these areas, approximately 60 percent of girls in younger cohorts were attending school, though their mothers were extremely variable in education attainment. Nepal's national infant mortality rate dropped 46 percent from 1971 to 1996 , and the total fertility rate declined 27 percent from 1981 to 1996 . The increased availability of health and contraceptive services would lead one to expect further declines from the still high levels of 1996 (infant mortality of 93, total fertility of 4.6). Analyses of surveys of women aged 15-49 years had shown associations of maternal schooling with reductions in child mortality and fertility, controlling for other socioeconomic variables. The Nepal Family Health Survey of 1996 (NFHS) revealed several pathways through which schooling might influence child survival and fertility among Nepal women. These included rising ages at marriage, more frequent use of maternal and child health services, and greater exposure to public health and family planning messages in the mass media. ${ }^{11}$

Several findings from previous research frame the problem for the current study. Norman Luther and Shyam Thapa have shown that use of prenatal care (number of visits, tetanus immunization) is associated with lower infant mortality, though their analysis does not attempt to forge a link with schooling. ${ }^{12}$ The NFHS report itself shows strong (unadjusted) associations of educational attainment with some prenatal care (as opposed to none), with seeing a doctor for prenatal care (as opposed to another health care provider), and with getting two or more tetanus toxoid injections. ${ }^{13}$ The report shows that 90 percent of the Nepalese women overall had heard of using oral rehydration salts (ORS) for a child's diarrhea. However, whereas only 23 percent of unschooled mothers whose children had a bout of diarrhea in the last 2 weeks had used ORS, 36 percent of those with some schooling had used ORS. Furthermore, only 31 percent of the unschooled reported mixing it correctly, while about 45 percent of those with schooling had done so. ${ }^{14}$

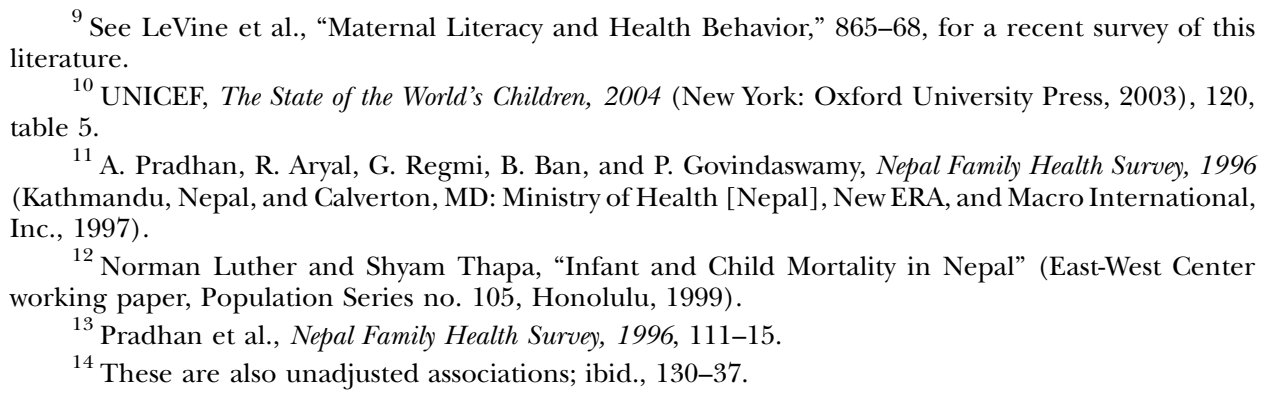

${ }^{11}$ A. Pradhan, R. Aryal, G. Regmi, B. Ban, and P. Govindaswamy, Nepal Family Health Survey, 1996 (Kathmandu, Nepal, and Calverton, MD: Ministry of Health [Nepal], New ERA, and Macro International, Inc., 1997).

${ }^{12}$ Norman Luther and Shyam Thapa, "Infant and Child Mortality in Nepal" (East-West Center working paper, Population Series no. 105, Honolulu, 1999).

${ }^{13}$ Pradhan et al., Nepal Family Health Survey, 1996, 111-15.

${ }^{14}$ These are also unadjusted associations; ibid., 130-37. 
ROWE ET AL.

Some pathways from maternal schooling to health behavior were investigated in the Kathmandu Valley, where women's schooling was most widespread. Analysis of the data on 117 women of Lalitpur District who reported a birth in the 5 years prior to the 1991 Nepal Fertility, Family Planning and Health Survey (NFS) showed that maternal schooling was associated with "medicalized pregnancy" (MP refers to prenatal care by a doctor, tetanus immunization, hospital delivery, and delivery by a doctor). These analyses controlled for age, childhood and adult SES, husband's schooling, urban or rural residence, and caste. ${ }^{15}$ In 1991, Lalitpur District had an infant mortality rate of 51 compared to 93 for Nepal as a whole, and 32 percent of evermarried women aged 15-49 had ever attended school there, compared to 14 percent for Nepal as a whole. Five years later, researchers studied 167 rural and urban Lalitpur mothers as part of the Project on Maternal Schooling of the Harvard Graduate School of Education. They found that literacy skills acquired in school not only increased mothers' comprehension of health messages in the media but literacy also enabled them to understand the instructions on the ORS label and to give an organized health narrative. These analyses controlled for socioeconomic factors, including schooling. ${ }^{16}$ The findings thus suggest that literacy could mediate the effects of schooling on the maternal health behaviors critical to child health. In light of these findings, larger-scale studies seemed necessary to assess maternal literacy in relation to health knowledge and behavior in places outside the Kathmandu Valley. Therefore, in 1998 UNICEF Nepal began planning the survey presented in this article.

\section{The Current Study}

In 2000, UNICEF Nepal together with the Center for Educational Research, Innovation, and Development (CERID) of Tribhuvan University in Kathmandu conducted an extensive survey of adult literacy skills and schooling and their relationship to health beliefs and care-seeking practices. Approximately 2,000 adults from two districts of Nepal completed a literacy test, a household survey, and a health beliefs and practices survey. This article presents results on a subset of this sample, including only mothers whose children were younger than age $5(n=482)$. We focus on mothers because of our interest in how the schooling of women and women's literacy skills and media activities relate to their health knowledge and practices, factors likely to influence their own health and the health and development of their children.

The 482 women with children under age 5 were drawn from the Kaski $(n=206)$ and Chitwan $(n=276)$ districts of Nepal. These specific districts were selected because their proportions of schooled women are higher than

${ }^{15}$ LeVine et al., "Maternal Literacy and Health Behavior," 867.

${ }^{16}$ Ibid., 873. 
in other districts outside Kathmandu Valley, and they are located in two different regions of Nepal, the hill region (Kaski) and the Terai lowlands (Chitwan). Surveys sampling the entire national population, like the Nepal Family Health Survey of 1996, have involved too few women who have ever been to school to examine the effects of schooling on other variables. For this reason, a district-level focus on populations with more maternal schooling was essential. Before describing our study in detail, we first explain the context of Kaski and Chitwan and provide information about the their health care and education systems.

Kaski district.-Located about 100 miles west of the capital city of Kathmandu in the western foothills of the Himalayas, Kaski is one of the most geographically varied of Nepal's 75 districts, with settlements at altitudes ranging from 2,000 to over 12,000 feet above sea level. It is also ethnically diverse, with Nepali-speaking Parbatiya Hindus living at the lower elevations and the Tibeto-Burman-speakers, chiefly Gurung and Magar peoples, at the higher elevations. Pokhara is the district headquarters and major town. Its subtropical climate at 2,000 feet, views of the Himalayas, and proximity to trekking routes have attracted foreign tourists. Prior to 1951 it was a small garrison town and market center for trade with Tibet in salt, grain, and wool run by Newar settlers from the Kathmandu Valley. In 1952 the population of Pokhara was 3,755. Thereafter, as a commercial, medical, and tourist center, and a popular retirement residence for Gurkha soldiers, it grew steadily. By 1970 it had a population just over 20,000. By 2001 it had grown close to 160,000 , making it a "submetropolitan" city.

Chitwant district. - Chitwan District, part of the hot, sea level region near the Indian border, was until the 1960s covered by malaria-infested jungle, sparsely populated by the Tharu people, and used primarily as a hunting preserve by Nepal's rulers. In 1952, the district population was 42,724, but in 1956 the government of Nepal opened up the district for development, and settlers moved in from the hill districts to the north (including Kaski) and from across the border in India to cut down the forests and till the fertile soil. Malaria was finally eradicated in 1969 , by which time the settlers were numerous. By 1991 the population had risen to 354,000, an eightfold increase in just 40 years. The majority today is Hindu, but there is also a significant Muslim population. Truck traffic along the north-south road (from India to Kathmandu) has spread HIV/AIDS in Chitwan, where it has been defined as a serious problem. About half of Nepal's population now live in the Terai as a whole, and Chitwan has become more advanced in terms of infrastructure and income than any district outside the urbanized Kathmandu Valley. The Royal Chitwan National Park also attracts a considerable volume of foreign tourists.

Schooling and health services. - Kaski and Chitwan, although they have different ecological settings, histories, and relations with the outside world, share 
ROWE ET AL.

in common the national policies that expanded schools and health services from the 1950s through the 1990s. In both districts there were very few schools, hospitals, and health posts at the beginning of that period and many by its end. Mass schooling, primary health care, and public health campaigns involving immunization and instruction have reached out even to remote villages. In addition to these government institutions and programs, private schools and clinics have expanded in recent decades, and they are preferred by those who can afford them.

Despite the institutional growth in education, fewer women than men had access to schools. Enrollments of girls lagged far behind that of boys for most of the period, especially in the rural areas of both districts. ${ }^{17}$ Many parents chose to send their sons but not their daughters to school or to terminate their daughter's schooling at a much lower level. When the sample mothers described in this article attended school, roughly during the 1980s, the countrywide primary school enrollment of girls was half that of boys. ${ }^{18}$

Schooling in Nepal is based on Western organizational and curricular models, but the schools-as in most poor countries-are of generally low quality by international standards. Buildings are often in disrepair, teachers unqualified, absenteeism frequent, and educational materials inadequate. Expanding enrollments have made matters worse and generated a demand for private schools, but largely after the women in this survey attended school. A recent analysis by Tirth Khaniya and James Williams suggests that school reform efforts (heavily funded by international donors) have had little effect on pupils' educational performance. ${ }^{19}$ Yet, as a previous study of mothers in the Kathmandu Valley showed the retention into adulthood of literacy skills learned in such schools, it was plausible to investigate this possibility and its consequences in health behavior elsewhere in Nepal. ${ }^{20}$

Research Questions

In this study we consider schooling, literacy skills, and media exposure as possible routes through which women learn health-related information pertinent to their own health and the health and development of their young children in Nepal. We posed three specific research questions:

1. How well do Nepali mothers of young children perform on a comprehensive literacy test, and what is the relationship between schooling and literacy skills?

\footnotetext{
${ }^{17}$ UNICEF, The State of the World's Children, 1999.

${ }^{18}$ Sharon Stash and Emily Hannum, "Who Goes to School? Educational Stratification by Gender, Caste, and Ethnicity in Nepal," Comparative Education Review 45 (2001): 354-78.

${ }^{19}$ Tirth Khaniya and James Williams, "Necessary but Not Sufficient: Challenges to (Implicit) Theories of Educational Change; Reform in Nepal's Primary Education System," International Journal of Educational Development 24, no. 3 (2004): 315-28.

${ }^{20}$ LeVine et al., "Maternal Literacy and Health Behavior," 873.
} 
2. Is schooling related to mothers' health knowledge and behaviors, controlling for socioeconomic and household factors?

3. Do literacy skills and media exposure mediate the relationship of maternal schooling to health knowledge and behaviors?

\section{Methods}

Sampling Plan

Our survey was designed to obtain a sample of mothers with children aged 12-60 months that was representative of each district, except that no more than half of the sample in either district could include unschooled women. This oversampling of women who had attended school was necessary in district populations with majorities of unschooled women in order to insure variation in school attainment sufficient for analysis of the effects of schooling on other variables. Thus, the sample used here is not representative of the population of all mothers of children aged 12-60 months in the Kaski and Chitwan districts in the year 2000. Each district was divided into five geographically defined sectors-north, south, central, east, and west-and in each sector 10 named sites-rural market areas, urban areas, and semiurban centers, for example-were selected for geographically dispersed sampling. Approximately 80 percent of the sites were rural. A snowball sampling method was adopted in which the field team visited households starting from a central neighborhood in each site. Once a household was identified that had children in the designated age range, all adult members were interviewed, given a literacy test, and asked to identify another household with a child in the designated age range. This snowball sampling method, that is, building a sample through respondent referral, is appropriate to situations where the target population is hard to find, as was the case for schooled women with preschool children in Nepal. ${ }^{21}$ However, snowball samples are often biased to include those who are interrelated and to exclude families that are isolated. Although our snowball sampling method limits the generalizability of this study, the geographically dispersed sampling frame reduces that bias. The samples in each site consisted of 7-10 households, and the average household contained three adults and three children. When the initial data collection was completed, we found that the Chitwan sample had an excessive proportion of unschooled women. Additional sites were therefore added until the proportion of unschooled mothers dropped below 50 percent (to 42 percent). This raised the total Chitwan sample to 276 mothers (as opposed to 206 in Kaski). Overall for the two districts together, there were 102 sites, 868 households, and 482 mothers of children 12-60 months of age. Table 1 presents descriptive statistics on mothers' schooling levels. On average,

${ }^{21}$ S. Berg, "Snowball Sampling," in Encyclopedia of Statistical Sciences, ed. S. Kotz and N. L. Johnson (New York: Wiley, 1988), 8:528-32. 
ROWE ET AL.

TABLE 1

Descriptive Statistics for Maternal Schooling (\% in Parentheses)

\begin{tabular}{|c|c|c|c|}
\hline & $\begin{array}{l}\text { Whole Sample } \\
\qquad(n=482)\end{array}$ & $\begin{array}{l}\text { Kaski District } \\
\quad(n=206)\end{array}$ & $\begin{array}{c}\text { Chitwan District } \\
\quad(n=276)\end{array}$ \\
\hline No schooling (0 years) & $177(37)$ & $60(29)$ & $117(42)$ \\
\hline Primary ( $1-5$ years) & $125(26)$ & $57(28)$ & $68(25)$ \\
\hline \multicolumn{4}{|l|}{ Lower secondary } \\
\hline$(6-8$ years $)$ & $70(14)$ & $33(16)$ & $37(13)$ \\
\hline \multicolumn{4}{|l|}{ Upper secondary } \\
\hline$(9+$ years $)$ & $110(23)$ & $56(27)$ & $54(20)$ \\
\hline Average years of schooling & $4.17[4.1]$ & $4.76[4.1]$ & $3.73[4.0]$ \\
\hline
\end{tabular}

women in the study had approximately 4 years of formal schooling. Women in Kaski had significantly more schooling than women in Chitwan $(t=$ $2.76, p<.01)$.

Procedures and Measures

A literacy test, household survey, and maternal health survey were administered orally in Nepali by native speakers to all 482 participants. Each measure and the variables of interest are described briefly below with descriptive statistics and specifics about compositing variables presented in the appendix.

Literacy test.-The literacy test measured functional, basic, and academic skills in reading, writing, and arithmetic. Measures were developed using guidelines from UNESCO, from Nepali functional literacy tests, and by choosing selected exercises from class 3 and class 5 textbooks for some academic skills. Functional skills included picture, letter, and word recognition; writing names and addresses and letter dictation; number recognition; and time reading. Basic skills included reading a sentence or an address written on an envelope, writing a dictated sentence or a description of a picture, and addition and subtraction. Academic skills included reading comprehension taken from Nepali textbooks, letter writing, writing responses to questions based on text passages, three-figure addition and subtraction, geometry, fractions, and word problems from Nepali textbooks. Scores for functional, basic, and academic skills were obtained on the reading, writing, and arithmetic sections separately and were summed to create a total score for the entire test.

Household survey.-The household survey focused on general household characteristics, family background, and social status. Information from this survey was used to create control variables for the following analyses. Specific control variables of interest include mother's age, husband's schooling, current household wealth, mother's parents' schooling, caste, district, joint family status, and urban or rural residence. Other variables, such as proximity to 
schools and health services, were not included because they were not significantly related to maternal schooling or outcome measures (see the app.).

Maternal health survey.-The maternal health survey contained detailed questions about women's health-related knowledge and practices. The survey was designed to tap important public health issues for women and children in Nepal. Specific measures were adapted from prior health surveys including a recent study by S. Burchfield and colleagues at World Education, Inc. ${ }^{22}$ It also included measures contained in the Nepal Family Health Survey of 1996. ${ }^{23}$ Two composite variables, Health Knowledge and Health Behavior, were created. Health Knowledge refers to women's knowledge of vaccines, contraceptives, uses of medicines, and causes and preventions of HIV/AIDS. Health Behavior represents maternal behavior related to her and her child's health during pregnancy as well as maternal behavior related to sanitation and keeping medicines in the home (see the app. for descriptive statistics and specific details of how composites were created).

Media experience.-As part of the health survey, mothers were asked about the frequency with which they read magazines or newspapers, listened to a radio, and watched television. These questions were considered important, as women could pick up health-related information from these sources. All three variables were related to one another and thus a composite was formed called Media (see the app. for descriptive statistics and details of the composite measure).

\section{Results}

To address our first research question we present descriptive statistics on women's scores on the literacy test and examine the relationship between years of schooling and literacy skills. To answer our second and third research questions we present multiple regression analyses showing the effects of schooling, literacy, media exposure, and controls on maternal health knowledge and behavior measures.

Schooling and Literacy Skills

There is wide variation in the distribution of women's scores on the literacy test, with total literacy scores ranging from zero to 152 points (out of a possible 163), a mean of approximately 75, and a large standard deviation relative to the mean of 50 points. There is a positive relationship between women's literacy skills and their years of formal schooling $(r=$

\footnotetext{
${ }^{22}$ Shirley Burchfield, H. Hua, Dyuti Baral, and Valeria Rocha, "A Longitudinal Study of the Impact of Integrated Literacy and Basic Education Programs on Women's Participation in Social and Economic Development in Nepal" (World Education, Inc. report supported by the United States Agency for International Development Office of Women in Development Contract no. HNE-C-00-96-900047-02, Boston, August 2002).

${ }^{23}$ Pradhan et al., Nepal Family Health Survey, 1996.
} 
ROWE ET AL.

$.74, p<.001)$. Women who had been to school longer scored better on the test, presumably because they had retained skills learned in school. This relationship is found even when controlling for women's age $(r=.71$, $p<.001)$. Figure 1 presents the average scores on the literacy test for women from each level of schooling. One-way analyses of variance (ANOVAs) show significant differences $(p<.001)$ between each level of schooling on reading, writing, arithmetic, and total literacy scores, with the exception of reading scores between lower and upper secondary education levels.

To understand the relationship between schooling and literacy skills, we then conducted a more detailed analysis of the literacy skills of women with different amounts of schooling. Table 2 presents the average functional, basic, and academic literacy scores in reading, writing, and arithmetic for women at each education level. Due to the unbalanced nature of the literacy test, where the different components (reading, writing, arithmetic) and levels (functional, basic, academic) were not equally weighted, each component and level was standardized to have mean zero and standard deviation (SD) of one. An additional standardized total literacy score was created that weights equally all components and levels. Both raw and standardized scores are presented in table 2. A total of 58 points on the literacy test was devoted to functional skills. Functional skills in reading include picture recognition, letter recognition, and word recognition. Functional skills in writing include writing your own name, village, and district; copying words and short sentences from written text; and writing letters and words heard through dictation. Functional skills in arithmetic include number recognition, writing a number heard through dictation, and time recognition. As table 2 shows,

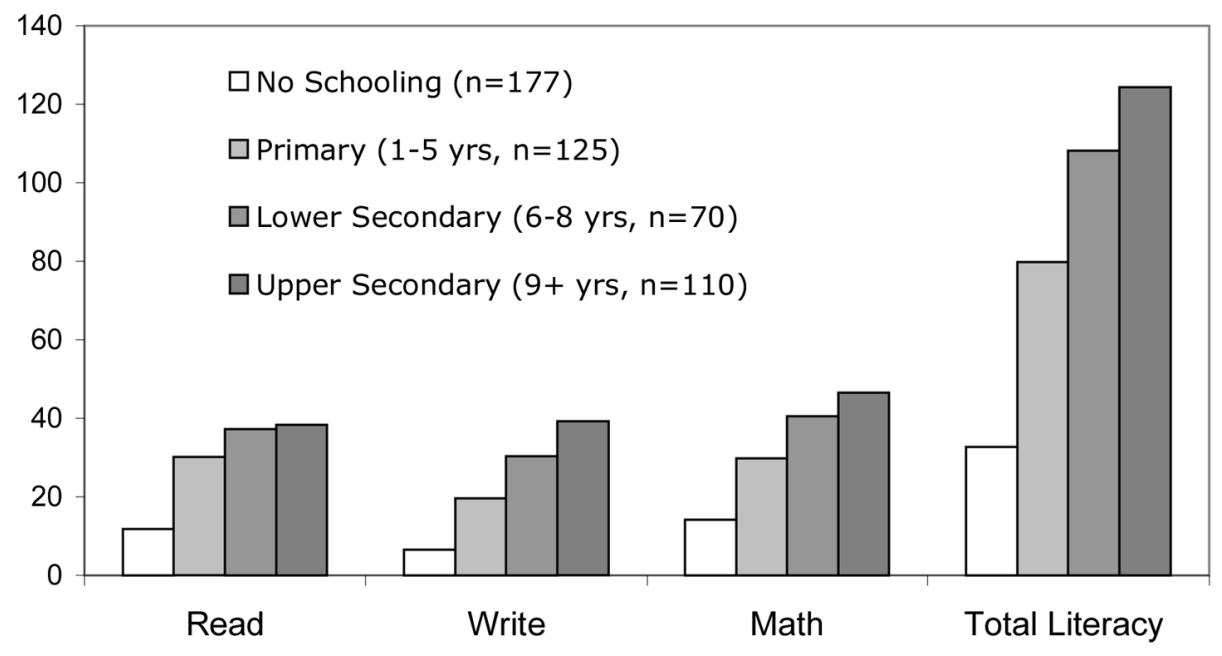

FIG. 1.-Mean reading, writing, arithmetic, and total raw literacy test scores by highest level of schooling attained. 
MATERNAL SCHOOLING AND HEALTH IN NEPAL

TABLE 2

Average Raw and Standardized (St) Functional, Basic, and Academic Skills in Reading, Writing, and Arithmetic for Mothers in Each Schooling Level and Overall

\begin{tabular}{|c|c|c|c|c|c|c|c|c|}
\hline & \multicolumn{2}{|c|}{ Reading } & \multicolumn{2}{|c|}{ Writing } & \multicolumn{2}{|c|}{ Arithmetic } & \multicolumn{2}{|l|}{ Total } \\
\hline & Raw & St & Raw & St & Raw & St & Raw & St \\
\hline Functional skills: & (Raw max & $=22)$ & (Raw max & $=22)$ & (Raw max & $=14)$ & (Raw max & $=58)$ \\
\hline No schooling & 8.90 & -.85 & 5.01 & -.84 & 4.51 & -.83 & 18.42 & -.87 \\
\hline Primary & 18.11 & .32 & 13.38 & .14 & 10.36 & .22 & 41.85 & .23 \\
\hline Lower secondary & 20.70 & .64 & 17.64 & .64 & 12.86 & .67 & 51.20 & .68 \\
\hline Upper secondary & 20.39 & .61 & 18.82 & .78 & 12.83 & .66 & 52.04 & .71 \\
\hline Total schooling & 15.62 & 0 & 12.17 & 0 & 9.14 & 0 & 36.93 & 0 \\
\hline Basic skills: & (Raw max & $=11)$ & (Raw max & $=30)$ & (Raw max & $=32)$ & (Raw max & $=73)$ \\
\hline No schooling & 1.86 & -.87 & 1.15 & -.68 & 9.54 & -.83 & 12.56 & -.85 \\
\hline Primary & 7.54 & .24 & 4.55 & -.24 & 18.72 & .01 & 30.82 & 0 \\
\hline Lower secondary & 9.60 & .64 & 9.13 & .35 & 25.36 & .62 & 44.09 & .58 \\
\hline Upper secondary & 10.02 & .72 & 15.36 & 1.15 & 28.74 & .93 & 54.12 & 1.00 \\
\hline Total schooling & 6.32 & 0 & 6.44 & 0 & 18.60 & 0 & 31.36 & 0 \\
\hline Academic skills: & (Raw max & $=10)$ & (Raw max & $=8)$ & (Raw max & $=14)$ & (Raw max & $=32)$ \\
\hline No schooling & 1.03 & -.80 & .47 & -.68 & .25 & -.52 & 1.75 & -.74 \\
\hline Primary & 4.59 & .05 & 1.76 & -.21 & .85 & -.32 & 7.21 & -.18 \\
\hline Lower secondary & 6.86 & .59 & 3.67 & .48 & 2.37 & .19 & 12.90 & .47 \\
\hline Upper secondary & 8.02 & .86 & 5.18 & 1.02 & 5.04 & 1.08 & 18.24 & 1.10 \\
\hline Total schooling & 4.40 & 0 & 2.34 & 0 & 1.81 & 0 & 8.56 & 0 \\
\hline Total literacy: & (Raw max & $=43)$ & (Raw max & $=60)$ & (Raw max & $=60)$ & $($ Raw $\max =$ & $=163)$ \\
\hline No schooling & 11.80 & -2.53 & 6.63 & -2.20 & 14.30 & -2.18 & 32.73 & -.86 \\
\hline Primary & 30.25 & .60 & 19.69 & -.31 & 29.94 & -.09 & 79.87 & .02 \\
\hline Lower secondary & 37.16 & 1.87 & 30.44 & 1.45 & 40.59 & 1.47 & 108.19 & .60 \\
\hline Upper secondary & 38.43 & 2.19 & 39.36 & 2.95 & 46.60 & 2.67 & 124.39 & .98 \\
\hline Total schooling & 26.34 & 0 & 20.95 & 0 & 29.54 & 0 & 76.83 & 0 \\
\hline
\end{tabular}

Note. - No schooling $=0$ years of formal schooling $(n=177)$, primary $=1-5$ years $(n=125)$, lower secondary $=6-8$ years $(n=70)$, upper secondary $=9+$ years $(n=110)$.

women with no formal schooling average approximately 18 out of 58 points, and thus as a group they demonstrate some limited functional skills. Women with some or complete primary education (1-5 years) average over 41 points, and women with some lower or upper secondary schooling (6+ years) average over 51 points. There was no difference between lower secondary ( $6-8$ years) and upper secondary $(9+$ years) schooling groups on functional skills in any domain. Thus, we can conclude that, on average, these functional literacy skills in reading, writing, and arithmetic are mastered upon completion of primary education.

Basic skills in reading include reading a simple sentence, reading and understanding an address written on an envelope, reading aloud a short letter from a child's teacher, and answering simple questions about the contents. Basic writing skills include writing a few sentences about what is going on in a picture and writing a short letter to a friend within a specified time limit. Basic arithmetic skills focus on addition and subtraction done in the market, including judging which price is highest, determining how much change one would receive after paying for an item, and determining how much it would cost to purchase two or three of an item or several different items together. There are a total of 73 points possible in the basic skills portion 
ROWE ET AL.

of the literacy assessment. Surprisingly, even those with upper secondary schooling (9+ years) average only 54 points. Thus, even those with the most schooling do not necessarily master these basic skills. There is, however, a difference of approximately 10 points on average between those with lower secondary and upper secondary education. These results show that additional years of schooling foster basic level skills. Those with some or completed primary education (1-5 years) on average do not master at least 50 percent of the basic skills and thus have limited basic literacy skills according to this measure.

The academic skills portion of the literacy test measured the ability to read aloud a lesson from a class 3 Nepali textbook and answer questions about what was read; to read a separate lesson and write down answers to questions about what was read; and to solve seven math problems, including three-figure addition and subtraction, multiplication, fractions, geometry, and word problems. There were a total of 32 possible points on the academic skills portion of the literacy test. Women with upper secondary schooling $(9+$ years $)$ averaged just over 18 points, and thus as a group have some academic-level skills compared to women with primary education (1-5 years), who averaged only 7 points on the academic skills measured.

Overall, these results suggest that literacy skills can be placed along a continuum from functional to basic to academic levels, and that much information is lost when people are clustered into categories of "literate" and "nonliterate." ${ }^{24}$ Had we not assessed literacy skills directly but designated everyone with more than 5 years of schooling as "literate" (the convention established in national censuses and accepted by UNESCO), then our definition of literate would encompass both women who were unable to read a simple sentence along with women who could read complex passages and give written answers to questions about the passage. Such an overbroad definition would tell us little about the distribution of women's skills in the socially valued literacy practices of Nepal.

\section{Health Knowledge and Behavior}

In this section we present multiple regression analyses that address the question of whether maternal literacy skills and media exposure mediate the relationship between maternal schooling and health knowledge and behavior, controlling for socioeconomic controls. Table 3 presents the zero order correlations between maternal health knowledge and behavior and schooling, literacy (standardized), media exposure, and controls. There are strong positive correlations between each predictor variable (schooling, literacy, and media exposure) and maternal health knowledge and behavior, with $r$-values ranging from 0.45 to $0.62(p<.001)$. Thus, women with more formal school-

\footnotetext{
${ }^{24}$ Daniel Wagner, Literacy, Culture, and Development: Becoming Literate in Morocco (New York: Cambridge University Press, 1993).
} 
MATERNAL SCHOOLING AND HEALTH IN NEPAL

TABLE 3

Simple Correlations (Pearson's $r$ ) of Maternal Health Knowledge and Behavior with Schooling, Literacy Skills, Media Exposure, AND Controls

\begin{tabular}{|c|c|c|}
\hline & \multicolumn{2}{|c|}{ Pearson's $r$} \\
\hline & $\begin{array}{l}\text { Knowledge } \\
(n=482)\end{array}$ & $\begin{array}{c}\text { Behavior } \\
(n=480)\end{array}$ \\
\hline \multicolumn{3}{|l|}{ Predictor measures: } \\
\hline Schooling & $.57 * * *$ & $.62 * * *$ \\
\hline Literacy & $.54 * * *$ & $.54 * * *$ \\
\hline Media & $.45 * * *$ & $.48 * * *$ \\
\hline \multicolumn{3}{|l|}{ Control measures: } \\
\hline Mother age & $-.25 * * *$ & $-.22 * * *$ \\
\hline Husband schooling & $.45 * * *$ & $.57 * * *$ \\
\hline Household wealth & $.43 * * *$ & $.53 * * *$ \\
\hline Parent schooling & $.25 * * *$ & $.24 * * *$ \\
\hline Caste $($ Brahmin $/$ Chetri $=1)$ & $.26 * * *$ & $.41 * * *$ \\
\hline Joint family & $.21 * * *$ & $.21 * * *$ \\
\hline Rural & $-.13 *$ & $-.25 * * *$ \\
\hline District (Chitwan = 1) & $.14 * *$ & $-.11 *$ \\
\hline
\end{tabular}

ing, women with stronger literacy skills, and women with more exposure to media are more knowledgeable about health-related matters and show more advanced health-related behaviors than their counterparts with less schooling, lower literacy skills, or less media exposure. All of the control variables were also related to maternal health knowledge and behavior, indicating the need for multivariate analyses examining the simultaneous effects of predictors and control variables on health knowledge and behavior.

We fit a series of multiple regression models to determine the effect of schooling on maternal health knowledge and behavior measures, controlling for socioeconomic variables. The analysis also reveals whether the effect of schooling on dependent measures is mediated by literacy skills and media exposure. These models are fit in accord with our theoretical model and following guidelines for using multiple regression to test for mediation. Reuben Baron and David Kenny suggest a three-step process for testing mediation. ${ }^{25}$ First, a relationship should be established between the independent variable (in this case maternal schooling) and the mediators (literacy and media exposure). Second, regression models should show the effect of the independent variable on the dependent variables (in this case the effect of schooling on health knowledge and behavior, controlling for socioeconomic controls). Third, the mediators should be included in the model with the independent variable, should be significant predictors of the dependent var-

${ }^{25}$ R. M. Baron and D. A. Kenny, "The Moderator-Mediator Variable Distinction in Social Psychological Research: Conceptual, Strategic, and Statistical Considerations," Journal of Personality and Social Psychology 51 (1986): 1173-82. 
ROWE ET AL.

iable(s), and the effect of the independent variable on the dependent variable must be reduced upon inclusion of the mediators. To satisfy step 1 , there is a significant positive relationship between maternal schooling and literacy skills $(r=.73, p<.001)$ and between maternal schooling and media exposure $(r=.55, p<.001)$. To follow steps 2 and 3 for each dependent measure of interest, we first present a model containing maternal schooling and controls, where controls were retained in the model if they were significant at the $p<.05$ level, to show the net effect of maternal schooling after accounting for socioeconomic controls. Next, we present a model adding literacy skills and media exposure to test the mediation hypothesis. For the models predicting health behavior, we also examine the effect of health knowledge as a predictor in a third model. Then we check for interaction effects and present a final, reduced model if necessary. Models testing the hypothesis that maternal literacy and media exposure mediate the relationship between schooling and maternal health knowledge are presented in table 4, followed by a series of models presented in table 5 examining the role of maternal schooling, literacy skills, media exposure, and health knowledge in explaining maternal health behaviors.

Model 1 in table 4 shows that maternal schooling, along with household wealth and district, explain about 39 percent of the variance in maternal health knowledge. Every additional year of schooling is associated with a positive difference of 0.22 on the health knowledge composite measure, controlling for household wealth and district. In model 2 literacy and media exposure are added to the model with schooling and controls. Here, the parameter estimate for the effect of schooling reduces by almost 50 percent, showing that literacy skills and media exposure partially mediate the relationship between schooling and health knowledge with significant controls already accounted for. The estimated coefficient for household wealth also decreases from model 1 to model 2, indicating that both household wealth

TABLE 4

Regression Models Predicting Maternal Health Knowledge on the Basis of Schooling, Literacy Skills, Media Exposure, and Controls $(n=482)$

\begin{tabular}{|c|c|c|}
\hline & \multicolumn{2}{|c|}{$\beta$-Coefficient (Standard Error) } \\
\hline & Model 1 & Model 2 \\
\hline Intercept & $-1.66^{* * *}(.13)$ & $-1.56 * * *(.16)$ \\
\hline Schooling & $.22 * * *(.02)$ & $.12 * * *(.02)$ \\
\hline Household wealth & $.15 * * *(.04)$ & $.10^{*}(.04)$ \\
\hline District $($ Chitwan $=1)$ & $.66 * * *(.13)$ & $.70 * * *(.12)$ \\
\hline Literacy (standardized) & & $.36 * * *(.09)$ \\
\hline Media & & $.32 * * *(.08)$ \\
\hline$R^{2}$ statistic & .3891 & .4335 \\
\hline
\end{tabular}


MATERNAL SCHOOLING AND HEALTH IN NEPAL

TABLE 5

Regression Models Predicting Maternal Health Behavior on the Basis of Schooling, Literacy Skills, Media Exposure, Health Knowledge, and Controls $(n=480)$

\begin{tabular}{|c|c|c|c|c|}
\hline & \multicolumn{4}{|c|}{$\beta$-Coefficient (Standard Error) } \\
\hline & Model 1 & Model 2 & Model 3 & Model 4 \\
\hline Intercept & $2.82 * * *(.25)$ & $2.87 * * *(.27)$ & $3.27 * * *(.27)$ & $3.36 * * *(.27)$ \\
\hline Schooling & $.17 * * *(.03)$ & $.09 * *(.03)$ & $.07 *(.03)$ & $.07 *(.03)$ \\
\hline Husband schooling & $.11 * * *(.03)$ & $.09 * * *(.03)$ & $.09 * * *(.02)$ & $.08 * * *(.02)$ \\
\hline Household wealth & $.30 * * *(.06)$ & $.28 * * *(.05)$ & $.23 * * *(.05)$ & $.23 * * *(.05)$ \\
\hline Caste $($ Brahmin/Chetri $=1)$ & $.59 * * *(.17)$ & $.65 * * *(.16)$ & $.64 * * *(.16)$ & $.66^{* * * *}(.16)$ \\
\hline Rural & $-.45^{*}(.19)$ & $-.36^{+}(.19)$ & $-.43 *(.19)$ & $-.42 *(.19)$ \\
\hline Literacy (Standardized) & & $.28 * *(.11)$ & $.18^{+}(.11)$ & $.37 * *(.13)$ \\
\hline Media & & $.28 * *(.10)$ & $.20 *(.09)$ & $.18^{*}(.09)$ \\
\hline Health knowledge & & & $.29 * * *(.05)$ & $.29 * * *(.05)$ \\
\hline Caste $\times$ literacy interaction & & & & $-.37 *(.15)$ \\
\hline$R^{2}$ statistic & .4960 & .5129 & .5414 & .5475 \\
\hline
\end{tabular}

Note. - Final model (model 4) $F=63.18, p<.0001$

${ }^{+} p<.10$.

$* p<.05$.

$* * p<.01$.

$* * * p<.001$

and schooling affect health knowledge partially through the effects of literacy and media exposure. In this model (model 2), maternal schooling $(p<$ $.001)$, literacy skills $(p<.001)$, and media exposure $(p<.001)$ are all positive predictors of health knowledge and combine with household wealth $(p<$ $.05)$ and district $(p<.001)$ to explain over 43 percent of the variance in maternal health knowledge. There were no significant interaction effects between district and any of the other variables in the model, thus model 2 is the final model predicting maternal health knowledge.

In model 2 (table 4), controlling for all other variables in the model, each additional year of maternal schooling is associated with a 0.12 positive difference on the health knowledge composite. In addition, controlling for schooling and all other variables in the model, every one standard deviation difference on the literacy measure is associated with a .36 positive difference on the health knowledge composite. Similarly, controlling for maternal schooling, literacy skills, and controls, each additional form of media exposure is associated with a 0.32 positive difference on the health knowledge composite. Finally, controlling for all other variables in the model, each additional point on the household wealth measure is associated with a .10 positive difference in maternal health knowledge. And, controlling for household wealth, schooling, literacy, and media exposure, mothers who live in Chitwan score an average 0.70 points higher on the health knowledge composite than mothers living in Kaski.

Model 1 in table 5 shows that maternal schooling, combined with significant controls, explains approximately 50 percent of the variance in health behavior and that every additional year of schooling is associated with a positive difference of 0.17 points on the health behavior composite measure, 
controlling for socioeconomic factors. In model 2, the parameter estimate for schooling reduces by approximately 50 percent when literacy and media are added to the model, again indicating that the net effect of schooling on health behavior (with controls in the model) is partially mediated by literacy skills and media exposure. In this model, maternal schooling $(p<.01)$, literacy skills $(p<.01)$, and media exposure $(p<.01)$ are all significant positive predictors of maternal health behavior and combine with controls to explain over 51 percent of the variance in maternal health behavior. In model 3 maternal health knowledge is added as an additional significant predictor $(p<.001)$, and the parameter estimates for schooling, literacy, and media all reduce slightly. These four predictors in model 3 combine with controls to explain approximately 54 percent of the variance in maternal health behavior. In model 4 we add the significant interaction effect between literacy and caste. In this final model, maternal schooling $(p<.05)$, literacy skills $(p<$ $.01)$, media exposure $(p<.05)$, health knowledge $(p<.001)$, husband schooling $(p<.001)$, household wealth $(p<.001)$, caste $(p<.001)$, rural versus urban residence $(p<.05)$, and the interaction between caste and literacy skills $(p<.05)$ all combine to explain approximately 55 percent of the variance in maternal health behavior.

In model 4 (table 5), controlling for all other variables in the model, each additional year of maternal schooling is associated with a 0.07 positive difference on the health behavior composite. In addition, controlling for schooling and all other variables in the model, the effect of literacy on health behavior differs depending on caste. For high caste women (Brahmin/Chetri castes), after controlling for other variables in the model, there is no added effect of literacy skills on health behaviors. For lower caste women (53 percent of the sample), higher literacy scores are associated with better health behaviors, even controlling for other variables in the model. Controlling for maternal schooling, literacy skills, and all other variables in the model, each additional form of media exposure is associated with a 0.18 positive difference in health behavior composite. A one-unit difference on the health knowledge composite is associated with a .29 positive difference on the health behavior composite. Furthermore, women living in urban sites, those with more household wealth, and those with husbands with more schooling have more advanced health behaviors, controlling for schooling, literacy, media exposure, health knowledge, caste, and the interaction between literacy and caste.

In sum, our findings from regression analyses support the theoretical model presented where the effect of maternal schooling on health knowledge and behavior is mediated, at least partially, by maternal literacy skills and media exposure, controlling for relevant socioeconomic factors. Furthermore, health knowledge is an additional predictor of health behavior. These specific findings and their implications are discussed further below. 


\section{Discussion}

Our findings suggest a strong relationship between maternal schooling and literacy skills, with literacy skills improving throughout the range of women's schooling. We also found that, controlling for socioeconomic controls, maternal schooling is a significant predictor of health knowledge and behavior. In addition, maternal literacy skills and media exposure partially mediate the effect of schooling on health knowledge and behavior, and they affect health outcomes. Maternal health knowledge appears to lead to maternal health behaviors, controlling for schooling, literacy skills, media exposure, and controls. The evidence from this study thus supports a theoretical model where literacy skills and media exposure help mediate the relationship of women's schooling on maternal knowledge and behaviors critical to child health. Before interpreting the findings of our analysis, we call attention to the value of direct and detailed literacy assessment demonstrated in this study.

Direct testing of literacy skills uncovered a continuous distribution of skills from functional to academic that spanned the full range of educational attainment levels from unschooled to upper secondary levels. This distribution, displayed in figure 1 and table 2, indicates the inadequacy of treating literacy as a dichotomy, and it provides far more information with which to examine questions such as the extent to which literacy acquired in school is retained in adulthood and has an impact on adult behavior. Furthermore, it supports the argument put forth by literacy researchers that the learning of academic literacy in school settings is a continuous process of development with a strong cognitive component that shows progress long after five years of schooling. ${ }^{26}$ This confirms what other literacy surveys have shown, that years of schooling or highest level of school attained does not always accurately measure literacy. ${ }^{27}$ In our Nepal sample, the poor showing of some women with secondary schooling might reflect the low quality of public schools in Nepal or their declining quality with the expansion that occurred during the years that our sample mothers attended school. ${ }^{28}$ The above-average showing of some women with little or no schooling might reflect effects of nonformal (adult literacy) education or literacy skills transmitted by members of their households (men and younger women) who have attended school. Furthermore, the fact that reading, writing, and arithmetic skills did not level off after a certain amount of formal schooling suggests that literacy skills are not simply acquired in the first 5 years or any other particular level of schooling but continue to grow during the postprimary years. This demonstrates the possibility that improvement in literacy skill may explain the decreased child

\footnotetext{
${ }^{26}$ Jeanne Chall, Stages of Reading Development, rev. ed. (Fort Worth, TX: Harcourt Brace, 1996).

${ }^{27}$ Wagner, Literacy, Culture, and Development.

${ }^{28}$ Khaniya and Williams, "Necessary but Not Sufficient."
} 
mortality associated with maternal schooling throughout the full range of educational attainment levels. ${ }^{29}$

Finally, literacy testing in this sample of mothers was beneficial in that it resulted in a reliable predictor of health knowledge and practices. Mothers with higher scores on the literacy test, even with their school attainment and socioeconomic controls held constant, showed more health knowledge and more advanced health behaviors than mothers with lower literacy scores. These results concur with previously mentioned findings from large scale studies in Morocco and Guatemala. ${ }^{30}$ Our findings support the conclusion that women's school-based literacy may promote personal health behavior affecting the mortality and morbidity of infants and young children.

Media exposure was an additional factor associated with health knowledge and practice. Mothers with more exposure to print and broadcast media have more health knowledge and more advanced health behaviors. Media exposure, along with literacy skills, partially mediated the effect of schooling on health knowledge and behavior. This finding confirms those from other studies and suggests that skills learned in school help mothers access print and broadcast media, which influence health outcomes. ${ }^{31}$ Our finding that media exposure explains some unique variance in health knowledge and behaviors is promising for the many public health campaigns in Nepal that communicate to audiences of all schooling levels through the broadcast media.

The results also suggest that maternal health knowledge is a significant predictor of maternal health behavior, controlling for schooling, literacy skills, media exposure, and controls. This finding supports the premise behind many public health media campaigns. It suggests, for example, that if mothers learn about the importance of prenatal examinations, they may be more likely to go to the doctor when pregnant. We should interpret this result with caution, however. The direction of causality is difficult to determine because our knowledge and behavior measures were made up of different public health factors and thus were not designed to test a causal claim.

Socioeconomic control variables (caste, husbands' schooling, household wealth, rural residence) played more of a role in explaining variance in health behavior than health knowledge. It may be that what a woman knows about health issues is most closely tied to her schooling, literacy skills, and media exposure, whereas her actual health practices also vary depending on the husband's wishes, cultural practices regarding the woman's caste/religion, and availability of resources due to household wealth and rural versus urban residence.

In the case of health knowledge, women in Chitwan performed better

${ }^{29}$ Cleland and van Ginneken, "Maternal Education and Child Survival in Developing Countries."

${ }^{30}$ Glewwe, "Why Does Mother's Schooling Raise Child Health in Developing Countries?"; Khandke et al., "The Role of Maternal Literacy in Child Health and Cognitive Development in Rural Guatemala."

31 Thomas, Strauss, and Henriques, "How Does Mother's Education Affect Child Height?" 
than women in Kaski. It seems plausible that due to a publicly recognized HIV/AIDS epidemic in the Chitwan district, more information about the subject was available and accessed by more women. Recall that the health knowledge measure contains knowledge of causes and preventions of HIV/ AIDS. This would explain the higher levels of health knowledge for women in Chitwan compared to women in Kaski.

In the case of health behavior, literacy had no effect for women of high caste (Brahmin/Chetri). Yet literacy had a positive effect for women of other castes (53 percent of the sample). On average, women of high castes scored above average on the health behavior measure, whereas women of other castes scored at or below average. This is not surprising, because Brahmins and Chetris (high-caste Hindus) have cultural practices for maintaining purity and avoiding pollution. For these women, cultural practices will persist regardless of their literacy score. Among women from lower castes, by contrast, the better their literacy, the better their health practices. In general, these district- and caste-level differences point to the need to add local knowledge of the indigenous culture and current situation of respondents to the generic protocols of a literacy and health survey.

From our survey we conclude that literacy assessment is a valuable instrument for investigating the pathways from formal education to maternal health behavior in the population of a developing country. Women's schooling, literacy, and media exposure each make important contributions to women's health knowledge and practices. Combined with measures of socioeconomic constraints and resources, these three factors explain how women respond to their biomedical environment. Our results suggest that further improvements in the quantity and quality of women's schooling, and in the more general public health media, can improve maternal and child health. This is particularly the case where women's schooling, demographic transition, mass media, and modern health care are recent developments, as is true in Nepal.

Appendix

Details on Household and Maternal Survey Participation

\section{Household Survey}

Eighty percent of our sample was rural, and 68 percent lived in joint families. There were no differences in urban versus rural residence or joint family status across districts. Approximately half of the women in the sample (47 percent) were of the highest castes (Brahmin and Chetri), thus, for the purposes of analyses, a dummy variable for caste was used measuring Brahmin/Chetri versus nonBrahmin/Chetri. Mothers averaged 26.3 years of age, and women's husbands averaged 7.2 years of formal schooling. Household wealth, a composite summing whether or not the current household has specific items (e.g., electricity, iron, telephone, bicycle, motorcycle, toilet, and type of house) averaged 2.5. The other 
measure of socioeconomic status, parent schooling, refers to the mothers' parents schooling and ranges from zero (neither parent had any education) to two (both parents had some education), with a mean score of 0.2 . There were no district differences in socioeconomic status for the samples on average. Furthermore, the relationship between women's schooling and husband's schooling was positive and quite strong $(r=.66, p<.001)$, yet men, on average, had almost twice as many years of formal schooling than their wives. Older mothers had fewer years of schooling on average than younger mothers $(r=-.31, p<.001)$, and mothers with more years of schooling had higher levels of household wealth $(r=.51, p<.001)$ and had parents with more schooling $(r=.37, p<.001)$ than did mothers with fewer years of schooling.

\section{Maternal Health Survey}

The Health Knowledge variable was created using principal components analysis to combine mothers' responses on the following items: the number of causes $(M=1.2, \mathrm{SD}=1.1$, range $0-5)$ and preventions $(M=1.3, \mathrm{SD}=1.3$, range $=$ 0-6) of HIV/AIDS she could name, the number of medicines she knew the uses for $(M=0.6, \mathrm{SD}=1.0$, range $0-5)$, knowledge of the polio vaccine $(M=0.7$, $\mathrm{SD}=0.4$, range $0-1)$, knowledge of what vaccines need to be given to children and when $(M=2.2, \mathrm{SD}=2.4$, range $=0-8)$, and the number of types of contraceptives she could name $(M=3.6, \mathrm{SD}=1.8$, range $=0-8)$. All measures were significantly positively related to one another with correlations ranging from $r=$ 0.17 to $r=0.85$ and an overall standardized alpha level of 0.77 . The first principal component was selected that weighted all variables positively with the most weight given to knowledge of causes and prevention of HIV/AIDS, followed by contraceptive knowledge, vaccine knowledge, use of medicines, and knowledge of the polio vaccine. This principal component contained 2.85 units of variance, 48 percent of the original variance in the included variables. The composite scores ranged from -2.89 to 6.90 with a mean of zero $(\mathrm{SD}=1.69)$.

Health Behavior is the sum of a mother's responses on the following nine items: whether or not she had prenatal care during her last pregnancy $(Y=386$, $N=94)$, took iron tablets during pregnancy $(Y=230, N=250)$, had all her tetanus toxoid vaccines $(Y=350, N=130)$, delivered her last child in a health facility $(Y=150, N=330)$, defecates in a latrine at the home $(Y=357, N=$ 123), washes her hands after defecation $(Y=324, N=156)$, uses iodized salt $(Y=286, N=194)$, keeps any medicine in the home $(Y=162, N=318)$, and treats unsafe water by boiling and/or filtering $(Y=134, N=346)$. All measures were significantly positively related to one another with the exception of the relationship between taking iron tablets while pregnant and treating unsafe water. Significant correlations ranged from $r=0.10$ to $r=0.39$, with an overall alpha level of 0.70 . Scores on the composite measure range from zero to nine with a mean of 4.96 ( $\mathrm{SD}=2.23)$. The sample size is 480 due to missing data for two mothers. Maternal scores on the Health Knowledge and Health Behavior composites were positively related $(r=.56, p<.001)$.

Media.-Seventeen percent of mothers said they read magazines or newspapers daily, 59 percent of mothers reported listening to the radio every day, and 48 
MATERNAL SCHOOLING AND HEALTH IN NEPAL

percent reported watching television at least once a week. Mothers in Kaski and Chitwan were equally likely to read daily, yet mothers in Kaski were more likely to listen to the radio daily $(t=8.02, p<.001)$, and mothers in Chitwan were more likely to watch television weekly $(t=-3.02, p<.01)$. A composite measure was formed in which 10 percent of mothers reported reading, listening to the radio, and watching television; 27 percent of mothers used two of these three forms of media; 39 percent used one form; and 24 percent reported no media activities. On average, mothers reported 1.2 forms of media exposure. Media exposure was positively related to maternal schooling $(r=.56, p<.001)$ and maternal literacy skills $(r=.46, p<.001)$. 